\title{
MICROMECHANICAL MODELLING OF DUCTILE FRACTURE - LOCAL APPROACH
}

\author{
Aleksandar Sedmak ${ }^{*}$, Marko Rakin ${ }^{2}$,Bojan Medjo ${ }^{2}$,Bashir Younise ${ }^{3}$ \\ ${ }^{1}$ Faculty of Mechanical Engineering, University of Belgrade, Kraljice Marije 16, \\ Belgrade, Serbia \\ ${ }^{2}$ University of Belgrade, Faculty of Technology and Metallurgy, Karnegijeva 4, \\ Belgrade, Serbia \\ ${ }^{3}$ University of El Mergib, Faculty of Engineering, Khoms, Libya
}

Received 09.12.2019

Accepted 13.01.2020

\begin{abstract}
Micromechanical modelling of ductile fracture by using the local approach has been presented as the review of previously obtained results for welded joints made of low alloyed high strength steel. Experimental work was performed on 3PB specimens and tensile panels, which were then modelled by finite element method, using two- and threedimensional meshes, respectively. The local approach was used to simulate both for crack initiation and growth during ductile fracture process.
\end{abstract} joints.

Keywords: micromechanical modelling; ductile fracture; local approach; welded

\section{Introduction}

Fracture is the most important phenomenon when considering material behaviour and structural integrity. The most common fracture mechanisms in metals are brittle (trans- or intergranular cleavage), Fig. 1a-b, ductile, Fig. 1c and fatigue. Although brittle fracture can be preceded by plastic deformation, its main feature is the absence of, and sudden appearance, at least in the final stage. Contrary to that, ductile fracture is characterised by slow process of initiation, growth and coalesce of voids, followed by large plastic deformation before the final failure, Fig. 2. Fatigue fracture is not in the scope of this paper.

Following differences in two basic fracture mechanisms for metallic materials, namely cleavage and ductile fracture, two different micromechanical models were developed by using the local approach. On one hand side, it was relatively simple to model brittle fracture, i.e. cleavage [1], whereas modelling of the more complex

\footnotetext{
*Corresponding author: Aleksandar Sedmak, asedmak@mas.bg.ac.rs
} 
mechanism of ductile fracture has to include void nucleation, growth and coalescence [2], Fig. 3. In this paper, micromechanical modelling of ductile fracture is presented as a compilation of previously accomplished research [3-15], based on the so-called local approach.

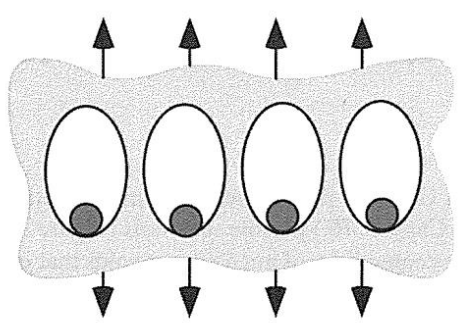

(a)

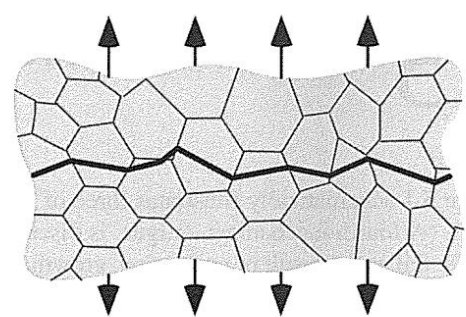

(b)

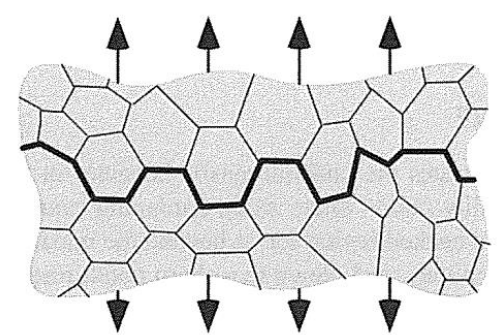

(c)

Fig. 1. Fracture types: (a) ductile, (b) transgranular cleavage, (c) intergranular cleavage.

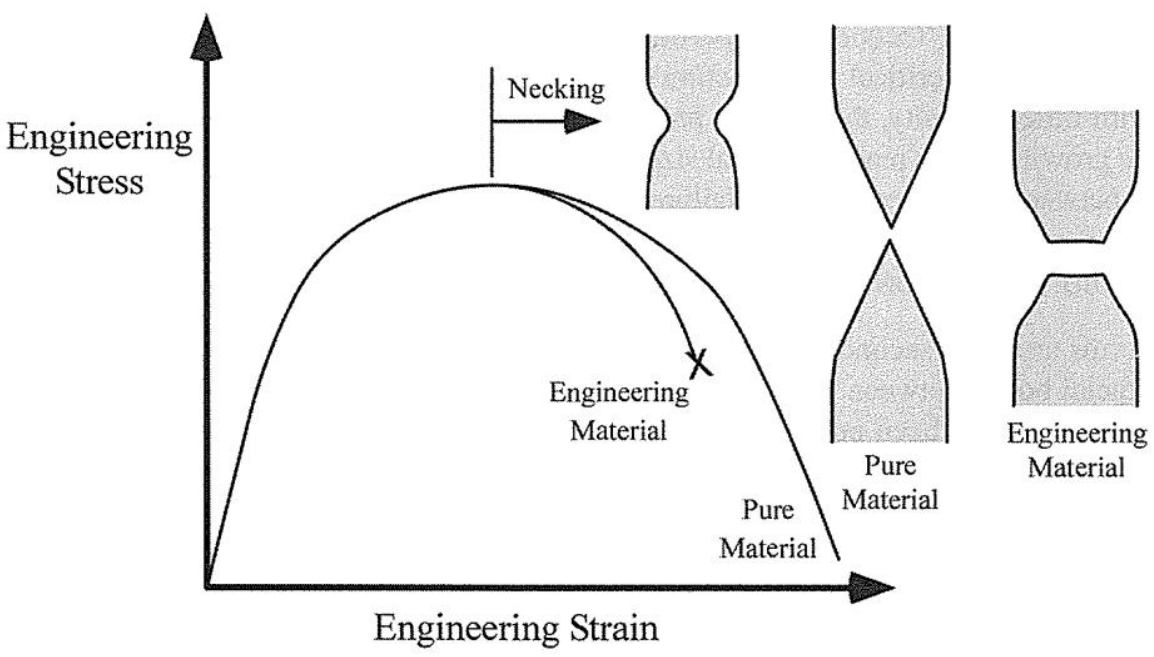

Fig. 2. Ductile stress-strain material behaviour [16]. 

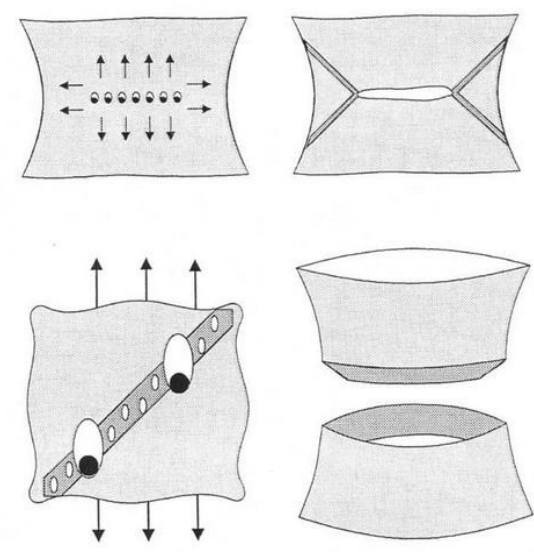

a)

b)
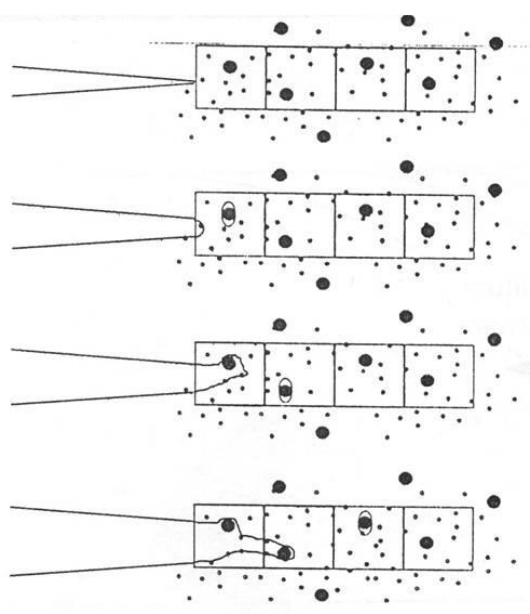

Fig. 3. Process of ductile fracture (a) without and (b) with initial crack [16].

The local approach to fracture combines a detailed experimental analysis, modelling of fracture mechanisms and implementation of models into a numerical simulation. It was developed in the early ' $80 \mathrm{~s}$, as described in the first MECAMAT International Conference [17]. During these early efforts, significant advances have been achieved in the understanding and modelling of the relationships between microscopic mechanisms and the macroscopic fracture behaviour, not only for brittle and ductile fracture but also for fatigue, creep, stress-induced corrosion and corrosion cracking, including oxidation-crack growth interaction. New topics and new methods have been investigated with promising results including brittle-ductile transition, anisotropy, nonproportional, thermomechanical and dynamic loadings [17-19]. Applications have been developed for pressure pipelines, including pipe ring specimen testing and numerical simulation [20-24], steam turbines [25-28] and welded joints [10-13, 29, 30]. Initially developed in the context of steel structures, e.g. pressure vessels [31], the local approach to fracture has been extended to other materials as well: metallic alloys, metallic foams, composites, polymers, elastomers, ceramics, concrete.

Significant progress has been made to transfer research results into standards and procedures, as provided by TC8 [32-36]. Also, some of the newest achievements have been presented during TC8 meetings in Paris and Cassino, and published previously, e.g. [37], as well as in doctoral theses, e.g. Yang Li [38]. Anyhow, we focus our attention here on micromechanical modelling of ductile fracture, especially in welded joints.

\section{Micromechanical modelling of ductile fracture}

Micromechanical modelling of round tensile specimens and notched tensile specimens with different notch radius, conducted in the early nineties, resulted in establishing the ESIS procedure [34], leading later on to the ESIS draft "Guidance on the local approach of rupture of metallic materials" [35]. More recent developments have been focused on voiding coalescence criterion, detailed microstructural analysis, and the effect of size, shape and distribution of voids [39, 40]. In any case, micromechanical 
modelling is complex issue comprising microstructure observation, experimental research and numerical simulation based on finite element method (FEM).

In the beginning, ductile fracture modelling, so-called uncoupled modelling, assumed that material behaviour is not affected by voids [41]. Such a simplified approach was based on the von Mises yield criterion only, without any damage parameter built into the constitutive equation. More complex, coupled models were developed soon afterwards [42], using constitutive equations developed by Gurson [43], based on damage parameter evaluated in the course of the finite elements (FE) analysis. Damage parameter was the void volume fraction, incorporated into the flow criterion, developed by Tvergaard and Needleman, establishing well-known Gurson-Tvergaard-Needleman (GTN) model [42], which can describe both damage development at a microscopic level and plastic strain at a macroscopic level. Finally, Zhiliang Zhang has developed the Complete Gurson Model (CG) [40], by incorporating the Thomason's limit load criterion [44] into the GTN model enabling successful modelling deep into the plasticity.

\section{Uncoupled modelling}

Whichever relevant field in fracture mechanics one tackles, it is always James Rice at the beginning $[41,45]$. Not different from that is the micromechanical modelling since it all started by the model of Rice-Tracey [30, 32], defining the void growth and indicating the strong effect of stress multiaxiality:

$$
\ln \left(\frac{R}{R_{0}}\right)=\int \alpha \cdot \exp \left(\beta \cdot \frac{\sigma_{m}}{\sigma_{e q}}\right) \cdot d \varepsilon_{e q}^{p}
$$

where $R$ stands for the mean void radius, $R_{0}$ is its initial value; $\sigma_{\mathrm{m}} / \sigma_{\mathrm{eq}}$ represents the stress triaxiality, and $d \varepsilon_{e q}^{p}$ is the equivalent plastic strain increment. The critical value of void growth ratio, $\left(R / R_{0}\right)_{\mathrm{c}}$, is the value at the crack initiation. Values of parameters $\alpha=0.283$ and $\beta=1.5$ for Rice-Tracey model are given in the original reference [41] as the constants for given steel. Rice-Tracey model was improved by Beremin [46], Huang [47] and Chaouadi et al. [48], but still in the scope of uncoupled modelling. Thus, the damage was calculated by post-processing routines, after FE analysis of the stress and strain fields.

\section{Coupled modelling}

In the coupled model of ductile fracture material is porous, with voids affecting the stress-strain state and plastic flow, as defined by GTN [42]:

$\phi=\frac{3 \sigma_{i j}^{\prime} \sigma_{i j}^{\prime}}{2 \sigma^{2}}+2 q_{1} f * \cosh \left(\frac{3 q_{2} \sigma_{m}}{2 \sigma}\right)-\left[1+\left(q_{1} f^{*}\right)^{2}\right]=0$

where $\sigma$ is the yield stress, $\sigma_{i j}^{\prime}$ the stress deviator, $\sigma_{\mathrm{m}}$ the mean stress, $q_{1}$ and $q_{2}$ parameters introduced by Tvergaard [49]. Finally, $f *$ is a function of the void volume fraction: 


$$
f^{*}=\left\{\begin{array}{lr}
f & \text { for } f \leq f_{c} \\
f_{c}+K\left(f-f_{c}\right) & \text { for } f>f_{c}
\end{array}\right.
$$

where $f_{\mathrm{c}}$ is the critical value at which void coalescence occurs. For $f *=0$, the plastic potential (2) is identical with that of von Mises. The parameter $K$ defines the slope of a sudden drop of the force, defining the final stage of ductile fracture - void coalescence, which leads to complete loss of the material load-carrying capacity.

In the initial phase of the ductile fracture, the voids nucleate mostly around the non-metallic inclusions. To quantify this micromechanism, the volume fraction of nonmetallic inclusions, $f_{\mathrm{V}}$, that can be determined using light microscopy, should be known [50]. There are two basic contributions to the increase of the void volume fraction, growth of existing voids and nucleation of new ones:

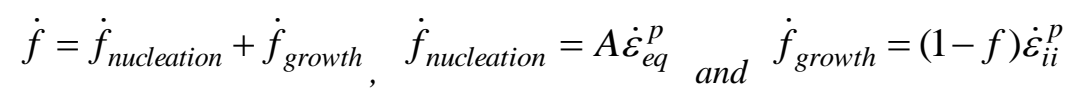

where $\dot{\varepsilon}_{i i}^{p}$ is the plastic part of the strain rate tensor.

Growth of nucleated voids strongly depend on stress and strain state, showing a typically exponential increase with the stress triaxiality. Furthermore, Chu and Needleman [51] proposed a model for the initiation of secondary voids, using normal distribution:

$$
A=\frac{f_{N}}{s_{N} \sqrt{2 \pi}} \exp \left[-\frac{1}{2}\left(\frac{\varepsilon_{e q}-\varepsilon_{N}}{s_{N}}\right)^{2}\right]
$$

where $f_{\mathrm{N}}$ denotes the volume fraction of secondary-void forming particles, $\varepsilon_{\mathrm{N}}$ is the mean strain at void nucleation, and $S_{\mathrm{N}}$ is the corresponding standard deviation.

Finally, the GTN model had been modified by Zhang et al. [40], who applied the Thomason's void coalescence criterion [44], to formulate the complete Gurson model (CGM), introducing new criterion for the onset of void coalescence:

$$
\frac{\sigma_{1}}{\bar{\sigma}}>\left(\alpha\left(\frac{1}{r}-1\right)+\frac{\beta}{\sqrt{r}}\right)\left(1-\pi r^{2}\right)
$$

where $\sigma_{l}$ is the maximum principal stress, $r$ the void space ratio, $a$ and $b$ parameters taken as constants, $a=0.1, b=1.2$ by Thomason [44], except that $a$ was taken as linearly dependent on hardening exponent $n$, in the CGM [40]. The void space ratio from Eq. (6) is given by [40]:

$$
r=\sqrt[3]{\frac{3 f}{4 \pi} e^{\varepsilon_{1}+\varepsilon_{2}+\varepsilon_{3}}}\left(\frac{\sqrt{e^{\varepsilon_{2}+\varepsilon_{3}}}}{2}\right)^{-1}
$$


$\varepsilon_{1}, \varepsilon_{2}$ and $\varepsilon_{3}$ being principal strains. Therefore, the critical void volume fraction $f_{c}$ is not a material constant in the CGM, i.e. it should be calculated during the FE analysis. Since its value depends on the strain field, the critical void volume fraction $f_{c}$ differs even within one finite element, having different values in different integration points, being especially important in welded joints.

\section{ESIS round-robin - modelling of ductile fracture initiation and growth}

The ESIS round robin on ductile fracture initiation has been performed in the early nineties of XX century on the low-alloyed steel $22 \mathrm{NiMoCr} 37$ (applied mainly for pressure vessels), tested on specimens in forged and heat-treated condition [33]. This was done in the scope of ESIS Technical Committee 8 (TC8) activities, in two phases, first experimental, and then numerical, using FEM for micromechanical modelling. Basic tensile properties were as follows: Yield Strength $R_{\mathrm{p} 0.2}=476 \mathrm{MPa}$, Ultimate Tensile Strength $R_{\mathrm{m}}=620 \mathrm{MPa}$.

Initial void volume fraction $f_{0}$ is determined by quantitative light microscopy as the volume fraction of inclusions [50]:

$$
V_{V}=A_{A}=\frac{A_{i}}{A_{T}}
$$

where: $V_{\mathrm{V}}$ and $A_{\mathrm{A}}$ are the volume and area fraction of detected inclusions, respectively; $A_{\mathrm{i}}$ is the area of the detected inclusions, and $A_{\mathrm{T}}$ is the measurement field area. Volume fraction, $f_{0}$, was determined as the mean value of area fraction for 100 measurement fields, providing the value $f_{0}=0.00226$ for the tested low alloyed steel, 22 NiMoCr 3 7. Typical optical micrographs of non-metallic inclusions in tested steel are shown in Figure 4.
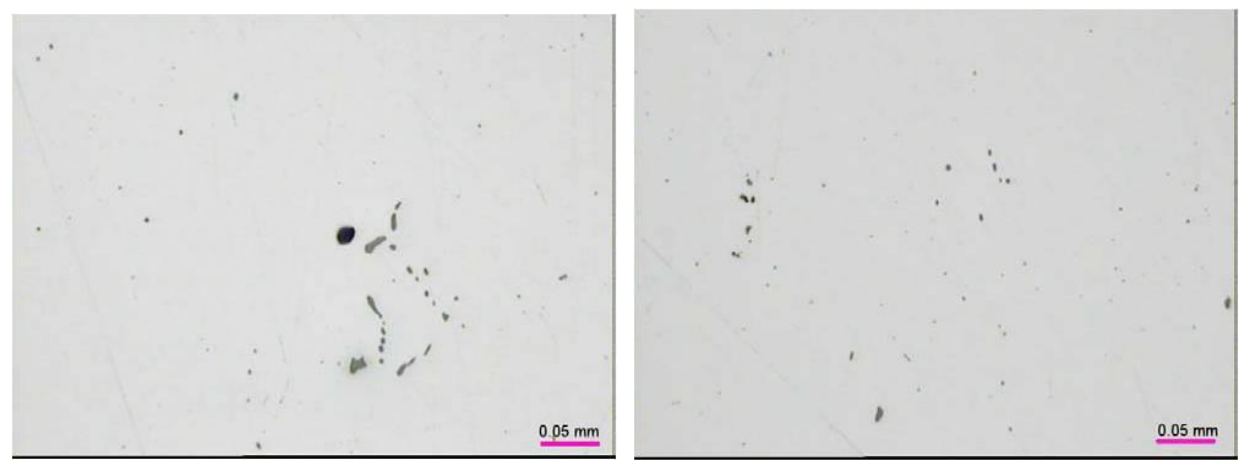

Fig. 4. Optical micrographs of non-metallic inclusions in tested steel [52].

The volume fraction of iron carbides is determined by using the lever rule on the metastable $\mathrm{Fe}-\mathrm{Fe}_{3} \mathrm{C}$ diagram for known carbon content $(0.22 \%)$ : 
weight $\%$ cem. $=\frac{0.22-0.025}{6.67-0.025} \cdot 100 \%=2.93 \%$

where 6.67 is the weight $\%$ of $\mathrm{C}$ in $\mathrm{Fe}_{3} \mathrm{C}$ and 0.025 is the weight $\%$ of $\mathrm{C}$ in ferrite. Since densities of structural steel and $\mathrm{Fe}_{3} \mathrm{C}$ particles are similar, the volume fraction of iron carbides was taken as 0.03 , as used later for $f_{\mathrm{N}}$ in Chu-Needleman formulation.

The mean free path between non-metallic inclusions was determined according to [50], using five horizontal measuring (scan) lines in each measurement field. Then the value of $N_{\mathrm{L}}$ is determined, representing the number of interception of oxides or sulphides per measurement line unit (in $\mathrm{mm}$ ). The mean free path $\lambda$, as the mean edge-to-edge distance between inclusions, is determined as follows:

$$
\lambda=\frac{1-A_{A}}{N_{L}}
$$

where $A_{\mathrm{A}}$ is the area fraction of inclusions. This procedure can is applicable if inclusions are located in each of the measurement fields since otherwise $\lambda$ cannot be calculated by eq. (10). In our case, non-metallic inclusions were present in all 100 fields of measurement, so that the average value of mean free path $\lambda$ is calculated as follows:

$$
\bar{\lambda}=\frac{\sum \lambda_{i}}{n}
$$

where $n$ is the number of measurement fields. According to this procedure, $\bar{\lambda}=$ $219 \mu \mathrm{m}$ was determined.

Standard tension specimen, shown in Figure 5, is used for calculation with RiceTracey and GTN criteria of initiation of ductile fracture. Material nonlinearity is modelled using true stress - true (logarithmic) strain curve, and large strain (updated Lagrangian) FE formulation. All other relevant details are given in reference [7].

(a)

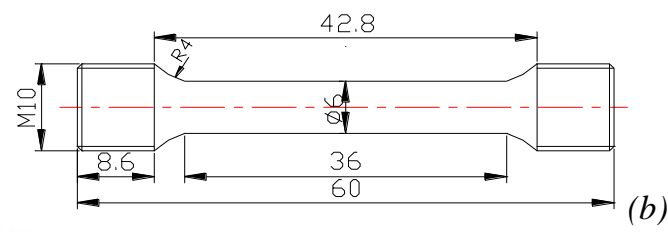

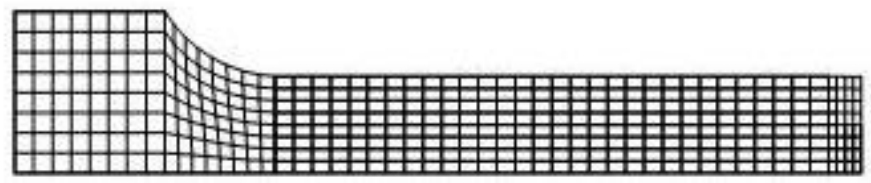

Fig. 5. Standard round tensile specimen - dimensions (a) and simulation by FE mesh (b). 
The GTN model was integrated into the FE software (ABAQUS www.simulia.com) to perform elastic-plastic FE calculations. Tvergaard-Needleman parameter value $q_{1}=1.5$ was used [42] for both cases, with and without secondary void nucleation, whereas parameter $D$ according to the Chu-Needleman model was determined for $\varepsilon_{N}=0.3, S_{N}=0.1$ and $f_{N}=0.04$, as the reference values [51] for the latter case.

Dependence between load, $F$, and reduction of cross-section, $\Delta D$, of a round specimen, is shown in Fig. 6, indicating that difference of FE calculation without nucleation of secondary voids and with traditional von Mises criterion are negligible almost to the point of the initiation of damage. Anyhow, calculation with secondary void nucleation predicts significant deviation from experimental data after the neck has been formed.

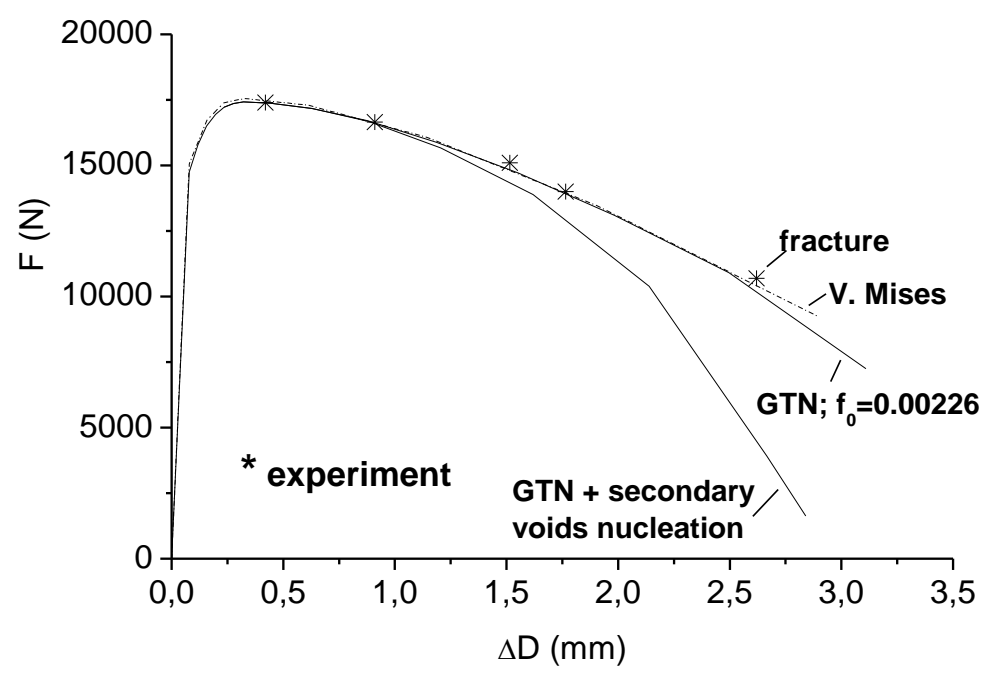

Fig. 6. Load, F, vs. reduction of cross-section, $\Delta D$, of the round tensile specimen [7].

Change of void volume fraction in the radial direction is shown in Fig. 7a for the prescribed displacements 3.5, 3.75 and $4 \mathrm{~mm}$, indicating specimen centre as the location of most severe damage and crack initiation. Therefore, the critical values of model parameters have been determined for the finite element in the specimen centre. The last step of numerical calculation (prescribed displacement $4 \mathrm{~mm}$ ) corresponds also to the specimen fracture, Fig. 7a.

Critical void volume fraction, $f_{\mathrm{c}}$, is determined using the point of the sudden drop of force caused by coalescence of voids in the necking process [7], $\Delta D \approx 2.63 \mathrm{~mm}$, Fig. $7 b$, being in good agreement with recommended values [7,35] for this steel $\left(f_{\mathrm{c}}=0.05\right)$ and the similar steel according to the American standard A508Cl.2 $\left(f_{\mathrm{c}}=0.045\right)$ [53]. The critical value $\left(R / R_{0}\right)_{\mathrm{c}}=3.045$ is obtained in the same way, as shown in the literature [2]. 


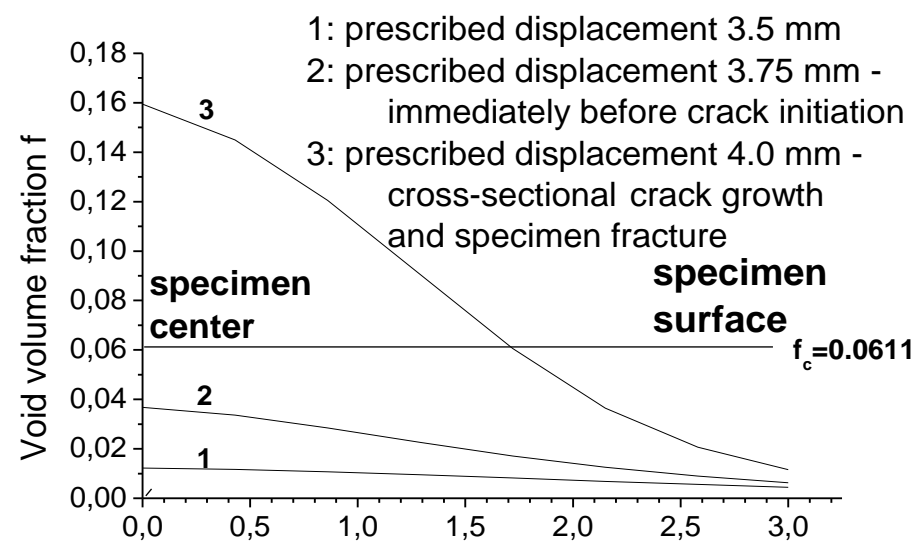

(a) Distance from the specimen center in radial direction $(\mathrm{mm})$

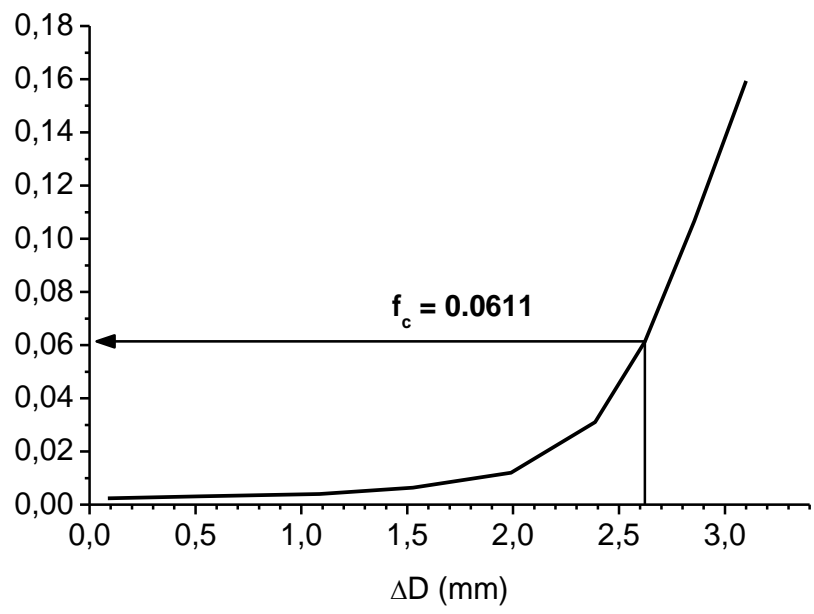

Fig. 7. a) Distribution of void volume fraction, $f, b)$ Critical void volume fraction, $f_{c}$.

In the second phase of the micromechanical analysis the onset of crack growth is determined on standard CT25 specimen (Figure 8a) [7], using six specimens to get curves to load - load line displacement and J-integral - crack growth. One half of the specimen is modelled by quadrilateral eight-noded isoparametric plain strain elements (Figure 8b), using the same true stress - true strain curve as for the tensile smooth specimen. Loading is introduced by prescribing displacements, in several steps. 

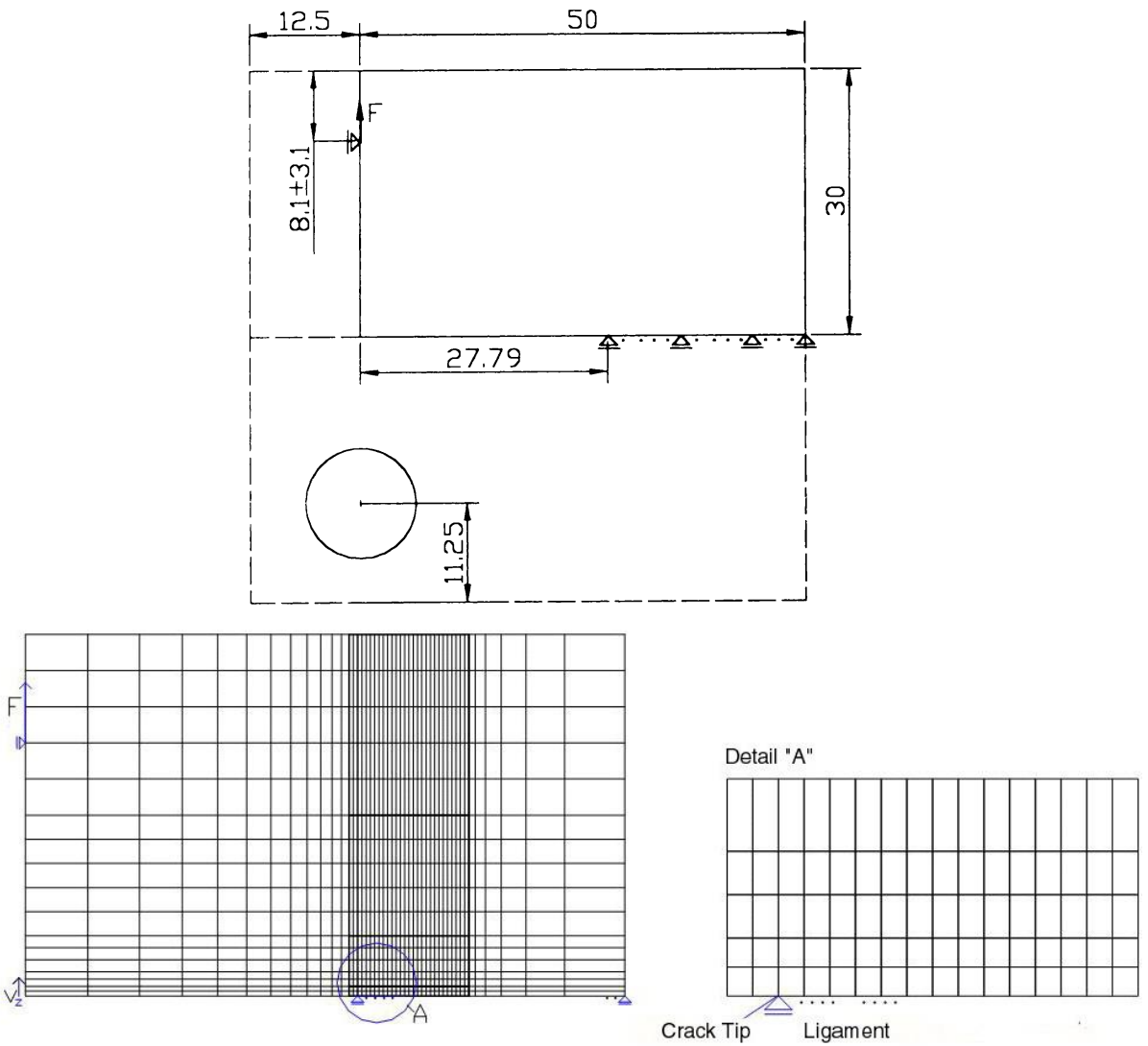

Fig. 8. a) CT specimen b) FE mesh c) detail near the crack tip [45].

Refined mesh without singular elements was used to model crack tip, Figure 8c. According to numerous researches [7], element size at the crack tip has to match the mean free path between the non-metallic inclusions $(\bar{\lambda}=219 \mu \mathrm{m})$. Therefore, the size of elements at the crack tip was chosen to be $0.2 \times 0.2 \mathrm{~mm}$ for both calculations: RiceTracey void growth model with von Mises yield criterion, and GTN model with the same initial void volume fraction value as in the tensile smooth specimen. Subsequent void nucleation is not taken into account.

Distribution of void volume fraction, $f$ near the crack tip, at the onset of crack growth, is shown in Fig. 9, indicating concentration of large values $(f>0.09)$ close to the crack tip and large variation ahead of the crack tip. 


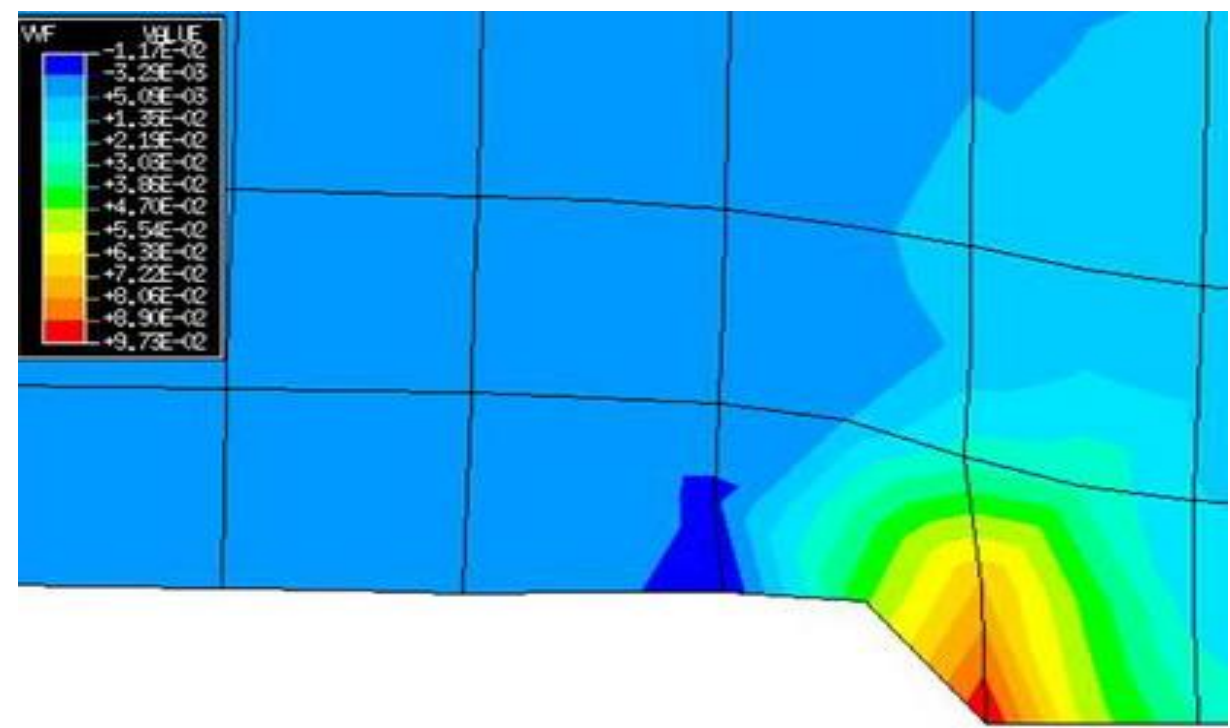

Fig. 9. Distribution of void volume fraction, $f$, ahead of the crack tip [7].

Based on FE calculation, load $F$ - load line displacement $V_{\mathrm{LL}}$ curves are established. The value of J-integral at crack initiation, $J_{\mathrm{i}}$, is obtained using the area below numerically determined curves, according to the standard expression:

$$
J_{i}=\frac{\eta U}{B_{n}\left(W-a_{0}\right)} \text { and } \eta=2+0.552\left(1-\frac{a_{0}}{W}\right)
$$

where $U$ is external work-area below $F-V_{\mathrm{LL}}$ curve, $W-a_{0}$ is ligament length and thickness $B_{\mathrm{n}}=20 \mathrm{~mm}$ due to $20 \%$ side grooves (specimen nominal thickness $B=25 \mathrm{~mm}$ ). Load line displacement $V_{\mathrm{LL}}$ at the onset of crack growth is determined for critical values $\left(R / R_{0}\right)_{\mathrm{c}}=3.045$ and $f_{\mathrm{c}}=0.0611$, obtained for the smooth specimen. Failure ahead of the crack tip is defined also for the same critical values, i.e. when $R / R_{0} \geq\left(R / R_{0}\right)_{\mathrm{c}}$ and $f \geq f_{\mathrm{c}}$. In this paper, failure criterion is applied at the Gauss point nearest to the crack tip (GP1), to calculate $J_{\mathrm{i}}$, as the more realistic option, following discussion in [7]. In this way, the experimental value $J_{\mathrm{i}}=230 \mathrm{~N} / \mathrm{mm}$ [7], was simulated closely, since GTN model produced $J_{\mathrm{i}}=220.4 \mathrm{~N} / \mathrm{mm}$, whereas Rice-Tracey model produced $J_{\mathrm{i}}=249.2 \mathrm{~N} / \mathrm{mm}$.

Anyhow, it is of utmost importance to keep in mind significant differences of the results in different Gauss points, as shown in Figure 10, where increase of void volume fraction, f, vs. load line displacement $V_{\mathrm{LL}}$, is presented for all Gauss points (GP1 - GP4) in the element at the crack tip. Together with the issue of the finite element size, this remains to be investigated further in future analysis, while some aspect of the problem has been already tackled $[7,45]$. 


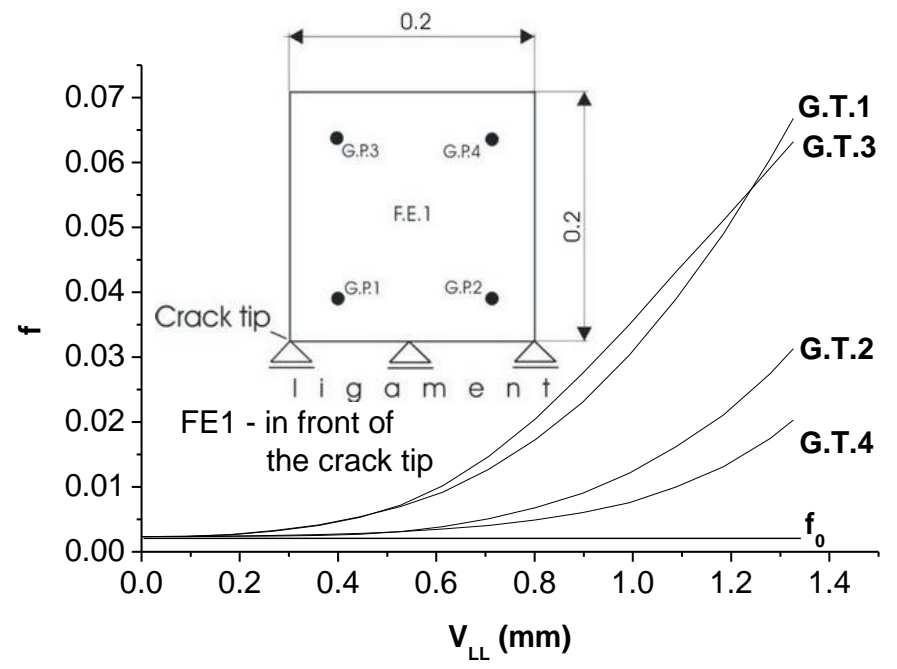

Fig. 10. Void volume fraction in Gauss points of the first FE in the ligament [7].

\section{Application OF MicroMechanical Modelling to welded joints}

Since welding is a complex process with abrupt structural and phase changes, one may not assume that welded joint has no cracks, even if non-destructive testing does not find any. Therefore, no wonder that welded joints attracted much attention in micromechanical modelling [10-13, 54-55], even though it has to be preceded by a detailed study of metallurgical and mechanical properties to ensure all necessary input data for different regions in heterogeneous material. Therefore, to start with, the quantitative microstructural analysis was performed to estimate the micromechanical material parameters: volume fraction of non-metallic inclusions $\left(f_{v}\right)$ and mean free path $(\lambda)$ between the non-metallic inclusions in base metal (BM), heat-affected zone (HAZ) and weld metal (WM) [52]. The initial porosity $\left(f_{0}\right)$ is assumed to be equal to the volume fraction of non-metallic inclusions $(f v)$. Volume fraction of void nucleating particles $\left(f_{N}\right)$, was calculated from the content of carbon in tested materials, using the carbon content in $\mathrm{BM}$ and filler metal for HAZ and WM, respectively [52], as presented in Table 2, together with volume fraction of non-metallic inclusions $(f v)$ and mean free path $(\lambda)$. Typical micrographs of non-metallic inclusions in the tested steel are presented in Fig. 11.

Table 2. Microstructural parameters of welded joint regions.

\begin{tabular}{lccc}
\hline Material & $F_{v}$ & $f_{\mathrm{N}}$ & $\lambda(\mu \mathrm{m})$ \\
\hline BM & 0.0094 & 0.014748 & 578 \\
HAZ & 0.0086 & 0.014748 & 497 \\
WM & 0.0194 & 0.010685 & 202 \\
\hline
\end{tabular}



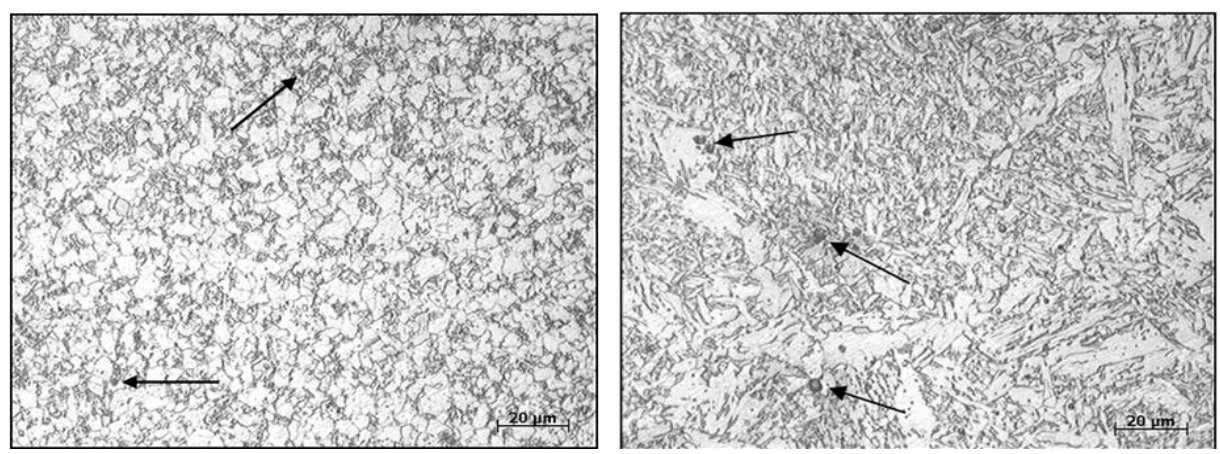

Fig. 11. Two optical micrographs of non-metallic inclusions in: (a) HAZ and (b) WM.

True stress - true strain curves in various zones of welded joint, especially the heataffected zone and its subzones (coarse grain - CGHAZ and fine grain - FGHAZ), are difficult to determine by conventional methods. Therefore, the iteration procedure based on the comparison of experimental and numerical results [56], was modified and applied to estimate true stress-true strain curves [52]. Toward this end, the smooth tensile plate was cut from welded plate to measure longitudinal strains at different load levels, in various regions of welded joints (WM, CGHAZ, FGHAZ and BM), using ARAMIS measuring system $[57,58]$ and then numerically modelled using ABAQUS 6.7 with threedimensional eight-node brick elements. According to differences in experimental and numerical results, parameters of true stress - true strain curves in all regions of the welded joint are corrected, until the agreement between the results becomes good enough, as shown in Fig. 12a, indicating good agreement after the $3^{\text {rd }}$ iteration. Figure $12 \mathrm{~b}$ presents the curves for all welded joint regions, whereas Figure 13 presents a comparison between the tested specimen and numerical true strain distribution. Material parameters obtained in this way are given in reference [52].
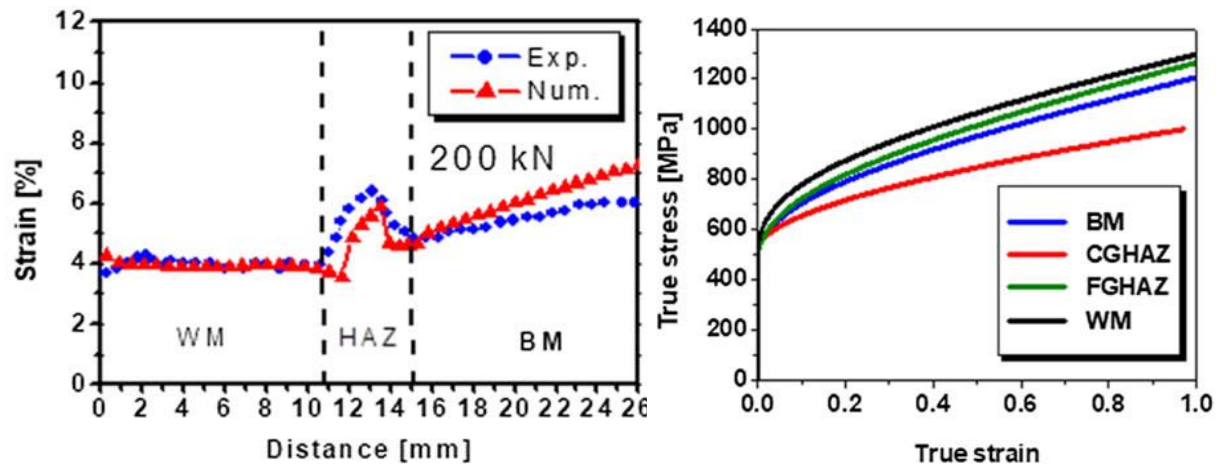

Fig. 12. a) Strain vs distance along the weldment, b) True stress-true strain curves. 


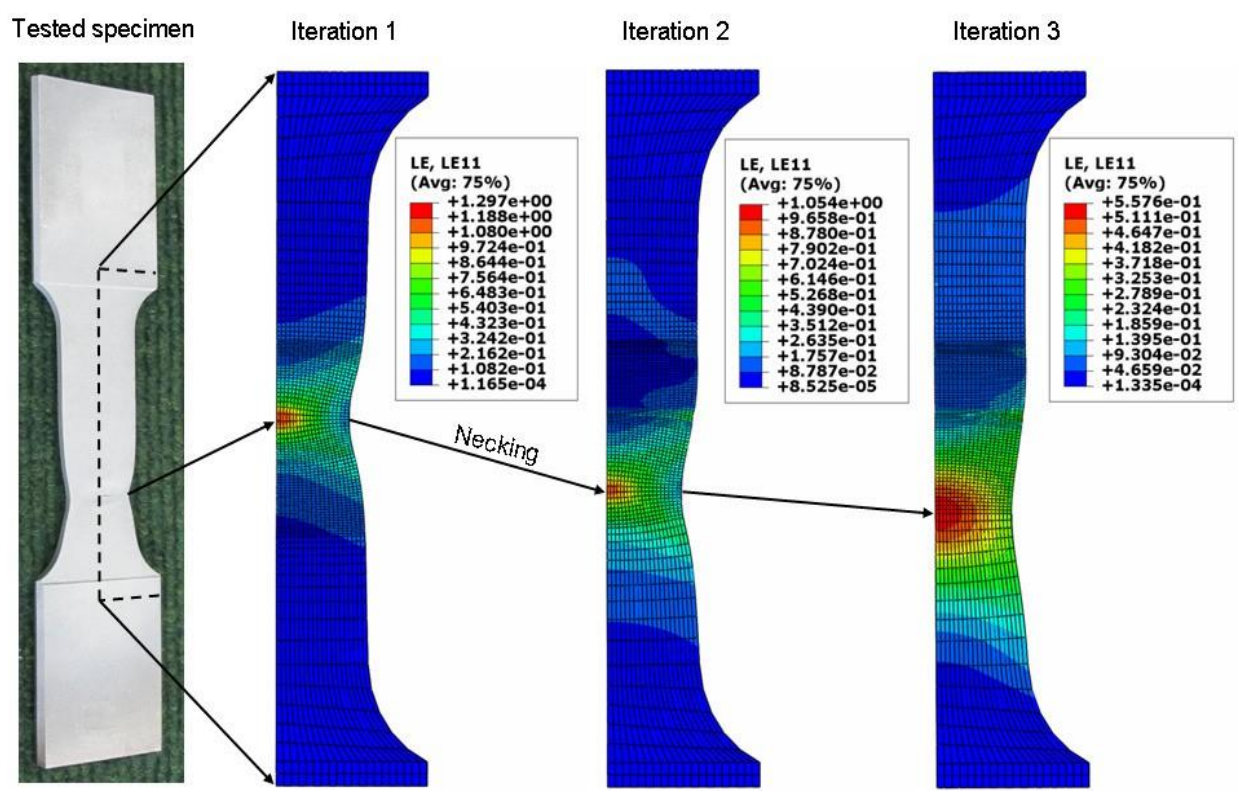

Fig. 13. Comparison between the tested specimen and longitudinal true strain distribution in numerical models for 3 iterations [52].

Testing and micromechanical modelling of welded joints were performed both for 2D and 3D problems, the former one on SENB standard specimens, Fig. 14, and the later one on Tensile Panels with surface cracks, as explained in [52]. Here, the 2D problem is analysed in some details, both for crack tip positioned in the WM, Fig. 14a, and in the HAZ, Fig. 14b.
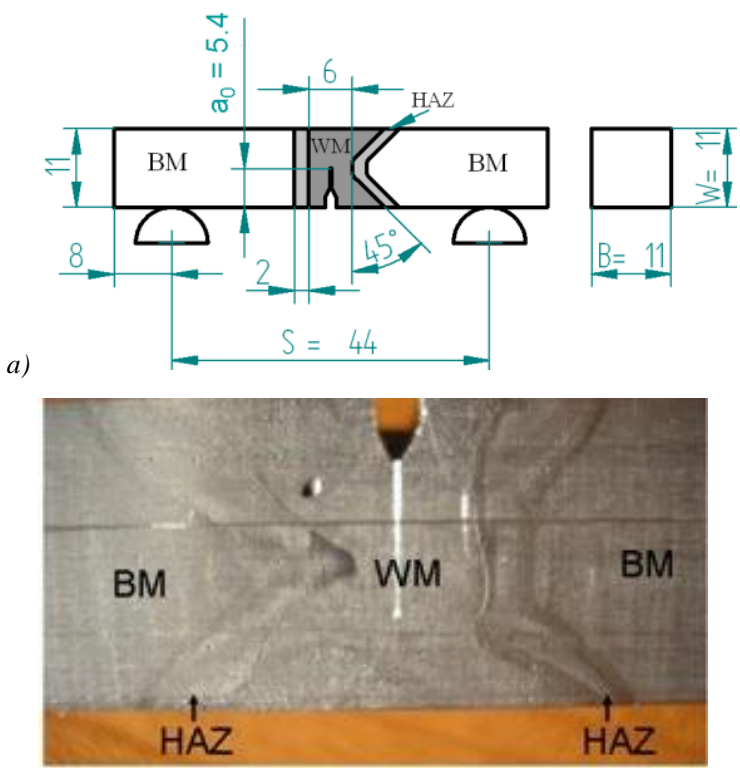

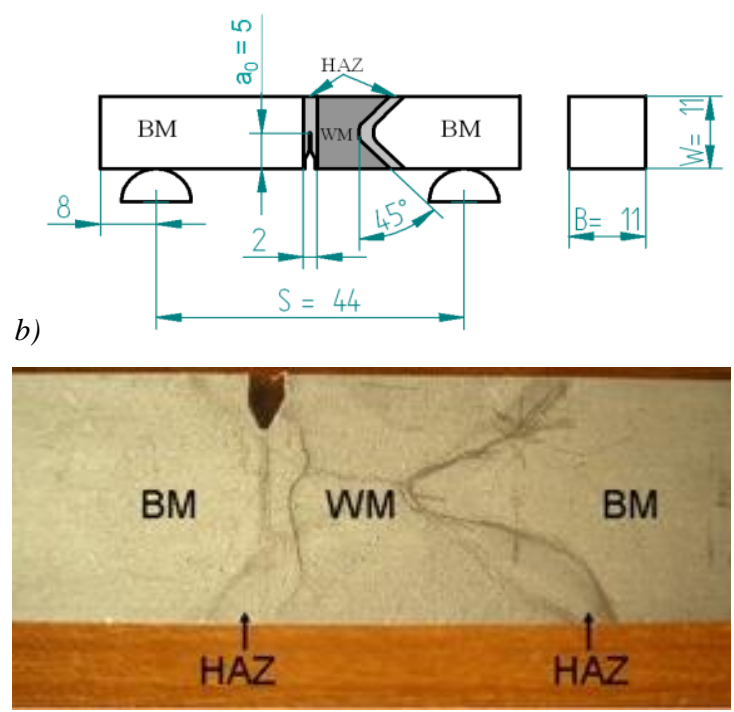

Fig. 14. Geometry and macrography of SENB specimen with pre-crack in a) WM, b) $H A Z$.

Both specimens were fatigue pre-cracked in a standard procedure [59]. The single specimen method was used and the unloading compliance technique was applied for stable crack growth monitoring. $J$-integral critical value, a measure of fracture toughness $J_{I c}$, is determined according to the ASTM E1820-08 [59] and given in Table 3.

\begin{tabular}{cc} 
Table 3. $J_{I c}$ values for SENB specimens [52]. \\
\hline specimen & $\begin{array}{c}\text { Critical J-integral, } J_{I c} \\
\left(\mathrm{~kJ} / \mathrm{m}^{2}\right)\end{array}$ \\
\hline SENB-HAZ & 84 \\
SENB-WM & 64.7 \\
\hline
\end{tabular}

Both 2-D models were analysed as plane-strain problems using isoparametric quadrangular eight-noded elements with $2 \times 2$ Gauss integration used for simulating crack initiation, and four-noded elements with full Gauss integration used for crack propagation. In front of the crack tip, squared finite elements $(0.2 \times 0.2 \mathrm{~mm}$ for the specimen with a pre-crack in WM and $0.5 \times 0.5 \mathrm{~mm}$ for the specimen with a pre-crack in FGHAZ) were used, Fig. 15, following the mean free path $\lambda$ between non-metallic inclusions in tested materials (see Table 2). 
a)

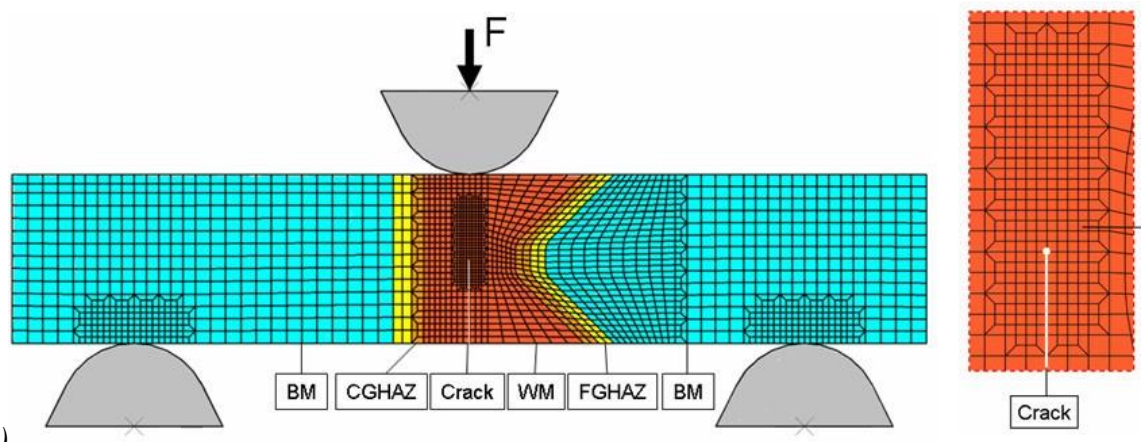

b)

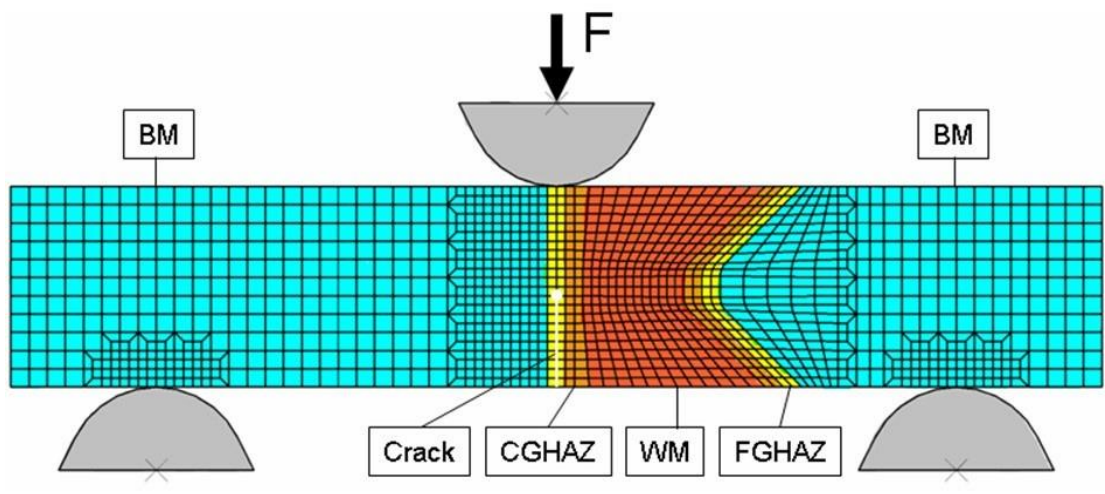

Fig. 15. Finite element mesh, a) crack in WM with enlarged mesh around the crack tip, b) crack in HAZ [52].

More detailed analysis is given in [52], including verification of FEM results by comparing with experimental ones, using plots of crack mouth opening displacement (CMOD) versus force $(F)$, as well as the effects of heterogeneity and constraint on ductile crack initiation and propagation. Here attention is focused only on crack growth, i.e. $J-R$ curves.

The crack growth $(\Delta \mathrm{a})$ has been simulated by tracing the path of completely damaged elements, shown in Fig. 16. This pattern is also visible in Fig. 17, where plastic zones at both crack tips are shown. Crack growth has been estimated by multiplying the original length of an element $\left(l_{\mathrm{c}}\right)$ with the number of completely damaged elements. The element is assumed to be completely damaged when the void volume fraction at final failure $f_{F}$ is reached according to the relation $f_{F}=0.15+f_{0}$. Then, the corresponding value of $J$-integral is calculated to construct crack growth resistance curves, Figure 18. One should notice good agreement between experimental and numerical results if the mesh size is taken following recommendations given in [52], i.e. if the size of element $l_{c}$ is similar to the average value of mean free path $\lambda$. 


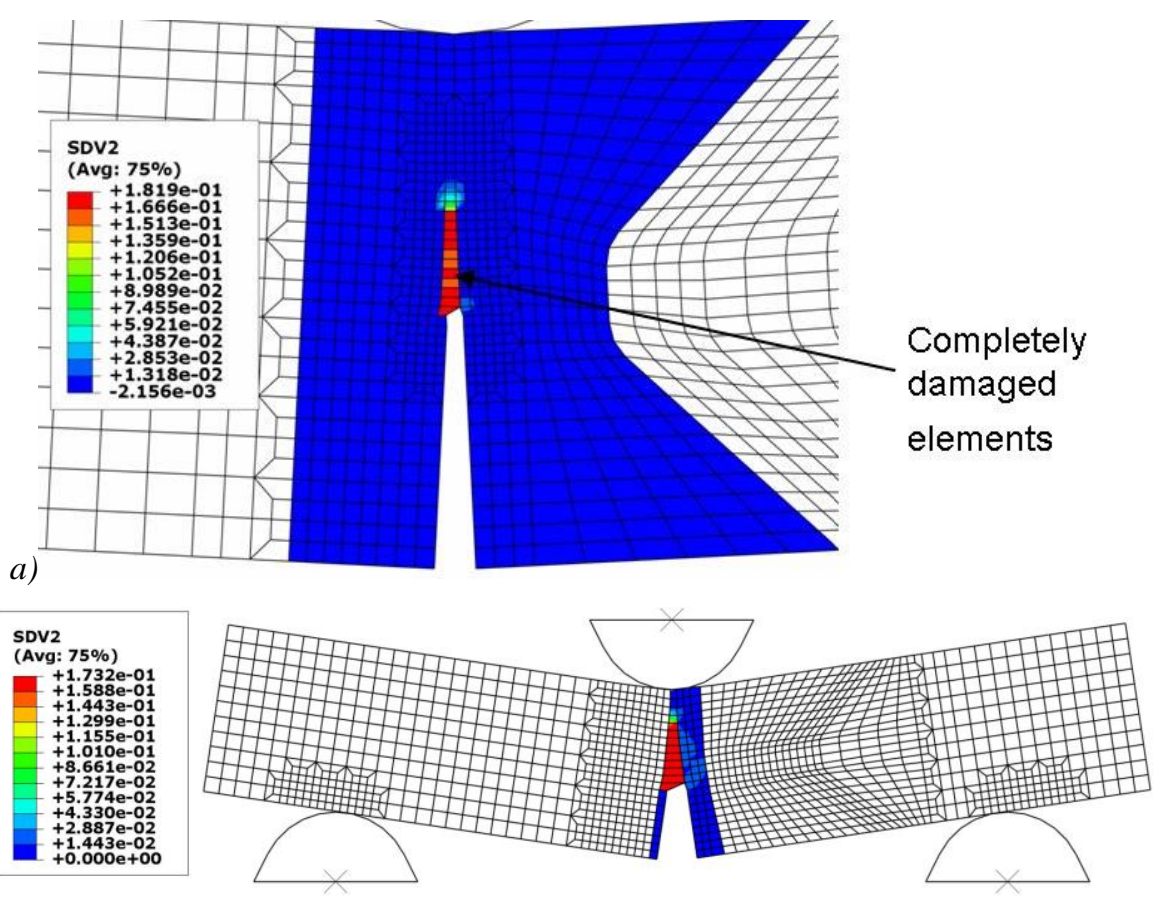

Fig. 16. Distribution of void volume fraction for SENB specimen with the crack in: a) WM, b) FGHAZ [52].
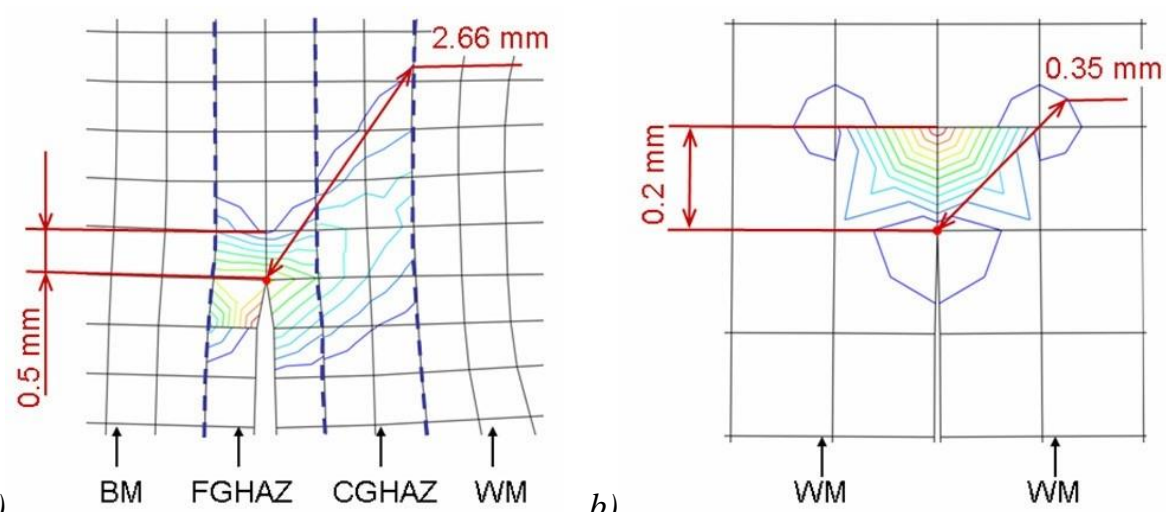

Fig. 17. Plastic strain zone size at the onset of crack growth for SENB specimens with the crack in: (a) HAZ, (b) WM. 


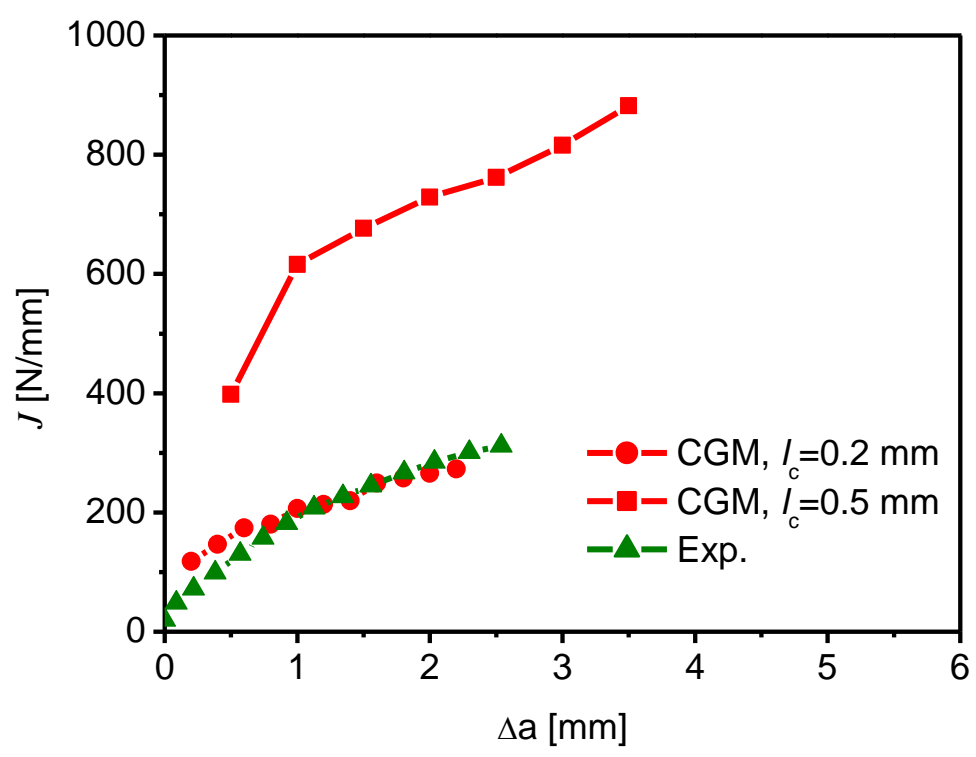

a)

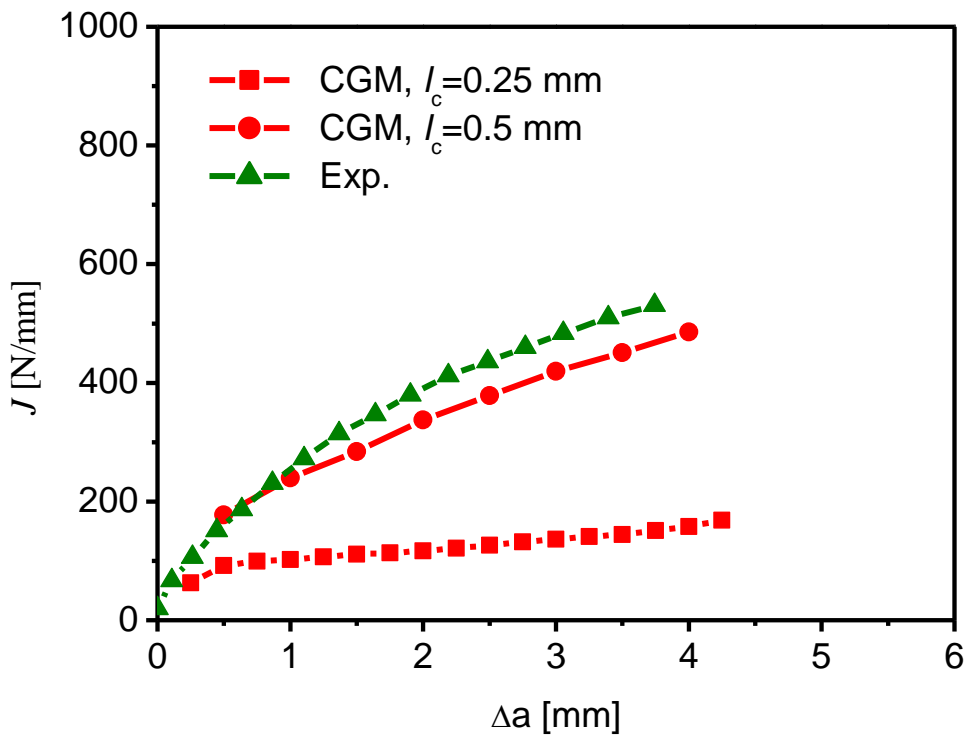

Fig. 18. Experimental and numerical J-R curves obtained from SENB specimen with the crack in a) WM, b) FGHAZ. 


\section{Conclusion}

Based on the results presented in this paper, one can conclude that micromechanical modelling presents a powerful tool in ever-increasing efforts to simulate ductile fracture under static load. It is not only theoretically well-developed but also the practical technique of modelling complex problems, such as crack initiation and growth in welded joints.

In respect to the material used in this research, i.e. HSLA steel welded joints, good agreement between experimental and numerical results has been obtained if the size of the element is similar to the average value of mean free path, both for two- and threedimensional problem. This phenomenon needs further elaboration.

\section{References}

[1] F.M. Beremin: Met Trans, 14A (1983) 2277-2287.

[2] M. Rakin, Z. Cvijovic, V. Grabulov, S. Putic, A. Sedmak: Engineering Fracture Mechanics, 71 (2004) 813-827.

[3] M. Rakin, N. Gubeljak, M. Dobrojević, A. Sedmak: Engineering Fracture Mechanics, 75 (2008) 3499-3510.

[4] M. Rakin M, Numerical analysis in local approach, In: Experimental and numerical methods of fracture mechanics in structural integrity assessment, Sedmak S. and Sedmak A. (Eds.), TMF-GOSA, Belgrade, (in Serbian), (1997) 345-352.

[5] M. Zrilić, M. Rakin, A. Sedmak, S. Sedmak, Experience in Fracture Mechanics Local Approach Application, Proceedings of the 6th International Scientific Conference on Achievements in the Mechanical Materials Engineering AMME97, Miskolc, (1997) 71-75.

[6] M. Zrilić, M. Rakin, A. Sedmak, S. Sedmak, Measurement Techniques in Local Approach to Fracture, Proceedings of the Fourth International Symposium on Measurement Technology and Inteligent Instruments, Miskolc, (1998) 358-361.

[7] A. Sedmak, M. Rakin, Application of fracture mechanics in assessment of structural integrity, In: From Fracture Mechanics to Structural Integrity Assessment, (Ed. S. Sedmak, Z. Radaković), DIVK-TMF, (2004) 373-386.

[8] M. Zrilić, M. Rakin, Z. Cvijovic, A. Sedmak, S. Sedmak, Structural integrity assessment by local approach to fracture, Proc. of 16th European Conference of Fracture ECF 16: Failure Analysis of Nano and Engineering Materials and Structures, Ed. E.E. Gdoutos, Alexandroupolis, Greece, (2006), published on CD by Springer.

[9] M. Zrilic, M. Rakin, N. Gubeljak, M. Dobrojevic, N. Krunich, A. Sedmak, Ductile fracture modelling of advanced metallic materials. EMMC9 MECAMAT, 9th European Congress on Mechanics of Materials, facilities of EDF "Les Renardières" Moret Sur Loing, France, (2006) 247-253.

[10] B. Younise, M. Rakin, B. Medjo, N. Gubeljak, D. Kozak, A. Sedmak: Technical Gazette, 18 (2011) 333-340.

[11] B. Younise, M. Rakin, N. Gubeljak, B. Medjo, A. Sedmak: Struct Integrity Life, 11 (2011) 51-56.

[12] B. Younise, M. Rakin, N. Gubeljak, B. Međo, M. Burzić, M. Zrilić, A. Sedmak: Materials and Design, 37 (2012) 193-201.

[13] B. Younise, M. Rakin, N. Gubeljak, B. Međo, A. Sedmak: Engineering Failure Analysis, 82 (2017) 435-445. 
[14] M. Rakin, Z. Cvijovic, V. Grabulov, A. Sedmak: Polish Materials Science and Engineering, 22 (2001) 741-744.

[15] M. Rakin, A. Sedmak, Z. Cvijović, M. Zrilić, S. Sedmak, Micromechanical approach - transferability of ductile fracture parameters, Proceeding of the 14th European Conference on Fracture - Vol III, EMAS Publishing, Krakow, (2002) 27-34.

[16] T.L. Anderson: Fracture Mechanics, CRC Press, London, 1995.

[17] J. Besson, D. Moinerau, D. Steglich, editors: Local approach to fracture, EUROMECH-MECAMAT, Mines, Paris, 2006.

[18] A. Needleman, V. Tvergaard: International Journal of Fracture, 101 (200) 73 97.

[19] Local Approach to Fracture, Edited by J. Besson, Les Presses de l'Ecole des Mines, Paris, 2004

[20] B. Međo, M. Rakin, N. Gubeljak, M. Arsić, Z. Šarkočević, A.Sedmak, Failure resistance of drilling ring casting pipes with an axial crack. Engineering Failure Analysis 58 (2015) 429-440.

[21] W. Musraty, B. Medjo, N. Gubeljak, A. Likeb, I. Cvijović-Alagić, A. Sedmak, M. Rakin: Engineering Fracture Mechanics, 175 (2017) 247-261.

[22] W. Musraty, B. Medjo, N. Gubeljak, A. Stefane, P. Vejić, D., Sedmak, M. Rakin: Theoretical and Applied Fracture Mechanics, 103 (2019) 102302.

[23] W. Musraty, B. Medjo, N. Gubeljak, A. Stefane, P. Vejić, D., Sedmak, M. Rakin: Procedia Strutural Integrity Theoretical and Applied Fracture Mechanics, 13 (2018) 1828-1833.

[24] D. Damnjanovic, D. Kozak, I. Gelo, N. Gubeljak: Theoretical and Applied Fracture Mechanics, Vol. 103 (2019) 102286.

[25] Zrilić M, Rakin M, Sedmak A, Aleksić R, Cvijović Z, Arsić M: Materials Science Forum, 518 (2006) 537-542.

[26] M. Rakin, A. Sedmak, Z. Cvijović, M. Zrilić, S. Sedmak: Strength of Materials, 36 (2004) 33-36.

[27] M. Zrilić, M. Rakin, A. Sedmak, S. Sedmak, Assessment of in-service degradation of steam pipeline steel by local approach method, Proceeding of the Conference: Life assessment and management for sructural components. Kiev, (200) 247-253.

[28] M. Zrilić, M. Rakin, Lj. Milović, Z. Burzić, V. Grabulov: Metalurgija, 46 (2007) 87-92.

[29] M. Dobrojević, M. Rakin, N. Gubeljak, I. Cvijovic, M. Zrilic, N. Krunich, A. Sedmak: Materials Science Forum, 555 (2007) 571-576.

[30] M. Rakin, B. Međo, N. Gubeljak, A. Sedmak: Engineering Fracture Mechanics, 109 (2013) 221-235.

[31] M. Rakin, Z. Cvijović, V. Grabulov, M. Zrilić, A. Sedmak, Determination of micromechanical ductile fracture parameters of pressure vessel steel, Proceeding of The 7th European Conference on Advanced Materials and Processes Euromat, Published on CD, Rimini, 2001.

[32] F. Mudry, M. Di Fant, A Round Robin on the Measurement of Local Criteria, Rapport Abrege N_RE 93.319, IRSID, St. Germain, 1993.

[33] W. Brocks, Numerical Round Robin on Micromechanical Models - Results, IWM-Bericht T 8/95, Fraunhofer Institut fuer Werkstoffmechanik (IWM), Freiburg, 1995. 
[34] European Structural Integrity Society, ESIS Publication P6-98: Procedure to measure and calculate material parameters for the local approach to fracture using notched tensile specimens, 1998.

[35] European Structural Integrity Society, ESIS Publication - Draft P9-02D: Guidance on local approach of rupture of metallic materials, 2002.

[36] G. Bernauer, W. Brocks, Numerical Round Robin on Micro-Mechanical Models - Results, ESIS TC8, GKSS Research Center, Geesthacht, 2000.

[37] G Testa, N Bonora, D Gentile, A Carlucci, Y Madi: Procedia Structural Integrity, 3 (2017): 508-516.

[38] Yang Li, Numerical Study on Ductile-to-Brittle Transition of Steel and its Behavior under Residual Stresses, Ph.D. thesis, NTNU, Trondheim, 2019.

[39] M. Rakin, A. Sedmak, V. Grabulov, N. Gubeljak, Z. Cvijović, Determination of initial damage parameters in Gurson-Tvergaard-Needleman model, 9th International Conference on Mechanical Behaviour of Materials, Published on CD, Geneva, 2003.

[40] Z.L. Zhang, C. Thaulow, J. Odegard: Engineering Fracture Mechanics, 67 (2000) 155-168.

[41] J.R. Rice, D.M. Tracey: Journal of Mechanics and Physics of Solids, 17 (1969) 201-217.

[42] V. Tvergaard, A. Needleman: Acta Metallurgica, 32 (1984) 157-169.

[43] A.L. Gurson: Journal of Engineering Materials and Technology, 99 (1977) 2-15.

[44] P.F. Thomason, Ductile Fracture of Metals, Pergamon Press, Oxford, 1990.

[45] A. Sedmak: Fatigue Fract Eng Mater Struct, 41 (2018) 2438-2474.

[46] F.M. Beremin, Experimental and numerical study of the different stages in ductile rupture: application to crack initiation and stable crack growth, In: Nemat-Nasser S., editor, Three-dimensional constitutive relations and ductile fracture, North-Holland Publ, (1981) 185-205.

[47] Y. Huang, Accurate dilatation rates for spherical voids in triaxial stress fields. Trans ASME, 58 (1991) 1084-1086.

[48] R. Chaouadi, P. De Meester, W. Vandermeulen: International Journal of Fracture, 66 (1994) 155-164.

[49] V. Tvergaard: International Journal of Fracture, 17 (1981) 389-407.

[50] American Society for Testing and Materials, Standard practice for determining inclusion content of steel and other metals by automatic image analysis. ASTM Standard E 1245-89. Philadelphia, 1989.

[51] C.C. Chu, A. Needleman: Journal of Engineering Materials and Technology, 102 (1980) 249-256.

[52] B. Younise, Micromechanical fracture analysis of high strength steel weldments, D.Sc. thesis, University of Belgrade, 2013.

[53] D.Z. Sun, R. Kienzler, B. Voss, W. Schmitt. Fracture mechanics twenty-second symposium. In: Atluri SN, Newman JC, Raju I Jr, Epstein JS, eds. ASTM STP 1131, Vol.II, Philadelphia: American Society for Testing and Materials; (1992) 368-378.

[54] M.C. Burstow, L.C. Howard, R.A. Ainsworth: J Mech Phys Solids, 46(5) (1998) 845-872.

[55] C. Betegón, I. Peñuelas: Eng Fract Mech, 73(13) (2006)1865-1877.

[56] R. Jovičić, A. Sedmak, K. Čolić, M. Milošević, N. Mitrović: CHEMICKE LISTY, 105 (2011) 754-757. 
[57] N. Mitrovic, M. Milosevic, A. Sedmak, A. Petrovic, R. Prokic-Cvetkovic: FME Transactions, 39 (2011) 55-60.

[58] N. Gubeljak: Structural Integrity and Life, Vol. 6, (2006) 65-74.

[59] ASTM E1820-08.

(c) (i) Creative Commons License

This work is licensed under a Creative Commons Attribution 4.0 International License. 